Cody, E Middleton, JB Harbone. New York: Alan R. Liss, p. 481-484, 1986.

${ }^{10}$ Mann, C.; Staba, E.J. In: Herbs, Spices, and Medicinal Plants: Recent Advances in Botany, Horticulture, and Pharmacology, edited by L.E. Craker and J.E. Simon, Phoenix, Arizona, Oryx Press, v. 1, p. 235-280, 1986.

${ }^{11}$ Jakolev, V.; Isaac, O.; Flaskamp, E. Pharmacological investigations with compounds of chamomile. VI. Investigations on the antiphlogistic effects of chamazulene and matricine. Planta Med, v. 49, p. 67-73, 1983.

${ }_{12}$ Achterrath-Tuckerman, U.; Kunde R. Pharmacological investigations with compounds of chamomile. V. Investigations on the spasmolytic effect of compounds of chamomile and Kamillosan on the isolated guinea pig ileum. Planta Méd., v. 39, p. 38-50, 1980.

${ }^{13}$ Jakolev, V.; Isaac, O.; Thiemer, K., Kunde, R. Pharmacological investigations with compounds of chamomile. II. New investigations on the antiphlogistic effects of (-)-alphabisabolol and bisabolol oxides. Planta Méd., v. 35, p. 125-140, 1979.

${ }^{14}$ Winter, C.A., Risley, E.A., Nuss, G.W. Carrageenan-induced edema in hind paw of rat as an assay for antiinflammatory drugs. Progress Society Biological Medicine, v. 11, p. 544$547,1962$.

${ }^{15}$ Rowley, D.A.;Benditt, E.P. 5-hydroxytryptamine and histamine as mediators of the vascular impure produced by agents which damage mast cells in rats. Journal of Experimental Medicine, v. 103, p. 399-415, 1959.

*Autor para correspondência:

Lucas Rossi Sartori

Laboratório de Fitofármacos

Universidade de Alfenas - UNIFENAS

Rod. MG, 179 - Km 0 CP 23

CEP 37130-000 - Alfenas (MG).

E-mail: fitofarmacos@unifenas.br

\section{Atividade antiinflamatória de quefir, um probiótico da medicina popular}

Diniz, R.O.; Perazzo F.F.; Carvalho, J.C.T.*; Schneenedorf, J.M.

Laboratório de Fitofármacos, Universidade de Alfenas

Resumo

O quefir é uma bebida fermentada originária do Cáucaso e formada por bactérias ácido-lácticas e leveduras, sendo utilizada por suas propriedades organolépticas e terapêuticas. O presente estudo avaliou a atividade antiinflamatória deste probiótico sobre modelo de indução de tecido granulomatoso e contorções abdominais induzidas por ácido acético, in vivo. Os resultados obtidos mostraram que o quefir inibiu a formação do tecido granulomatoso, bem como o número de contorções abdominais causadas por ácido acético, quando comparado ao grupo controle. Desta forma, pode-se sugerir uma possível ação antiinflamatória.

\section{Abstract}

Kefir is a fermented beverage with its origin in Caucasian region, formed by acid-lactic bacteria's and yeasts, and used due to its organoleptic and therapeutic properties. The present study evaluated the possibility of an antiinflammatory activity for induction of granulomatous tissue in rats and writhing test in mice. The results obtained shown that the kefir has inhibited the formation of the granulomatous tissue, as well as the number of writhings induced by acetic acid as compared to a control group. In this way the authors suggest a possible antiinflammatory action.

O quefir é uma suspensão de microrganismos simbiontes formado por um grande número de cepas de bactérias (predominantemente ácido-lácticas - BAL) e de leveduras, ambos encapsulados em uma matriz de polissacarídeos secretados pelas primeiras. Historicamente, o quefir é originário das montanhas do Cáucaso, havendo citações místicas de que seria "um presente do profeta Maomé ao seu povo, para a cura de todos os males"1. Em eslavo, Kephir significa "bem-estar".

$\mathrm{O}$ quefir produz uma bebida fermentada utilizada no ocidente por suas propriedades organolépticas e uso tradicional na medicina popular. Seu produto fermentado resulta em uma solução ácida contendo compostos aromáticos, gás carbônico e etanol ${ }^{2}$. Macroscopicamente o quefir se apresenta em grãos gelatinosos, medindo de 3 a $20 \mathrm{~mm}$ de tamanho e com propriedades organolépticas definidas para cada combinação microbiológica.

Os benefícios que este produto apresenta incluem redução dos efeitos de intolerância à lactose ${ }^{3}$, imunomodulação ${ }^{1}$, 
proteção contra microrganismos patogênicos ${ }^{4,5}$, balanço da microbiota intestinal ${ }^{6}$, atividade anticarcinogênica ${ }^{7}$ e regeneração hepática ${ }^{8}$, entre outras.

O presente estudo avaliou a possível atividade antiinflamatória deste probiótico sobre modelo de indução de tecido granulomatoso e contorções abdominais induzidas por ácido acético.

A administração de $1,0 \mathrm{ml} /$ dia de quefir levou à formação de 427,51 \pm 30,64 mg de tecido granulomatoso, sendo estatisticamente diferente do grupo tratado com dexametasona $(325,08 \pm 28,20 \mathrm{mg})$, mas diferente do controle, que apresentou $731,15 \pm 30,64 \mathrm{mg}$ (figura 1).

No ensaio de contorções abdominais o resultado foi similar ao da indução de tecido granulomatoso. $\mathrm{O}$ grupo tratado com quefir apresentou número total de contorções de $29,1 \pm 1,1$ significativamente diferente do grupo tratado com indometacina $(25,1 \pm 1,4)$ e ambos do grupo controle $(40,3 \pm 3,2)$ (figura 2).

$\mathrm{O}$ ensaio de indução de tecido granulomatoso é um método utilizado para determinação de uma possível atividade antiinflamatória sobre processos crônicos. A administração diária por via oral de $1 \mathrm{ml}$ de quefir durante 6 dias inibiu a formação do tecido granulomatoso em $42 \%$, quando comparado ao grupo controle e a inibição causada pela dexametasona aplicada topicamente foi de $51 \%$.

O mecanismo do desenvolvimento de contorções abdominais por ácido acético envolve a produção de prostaglandinas, em especial, $\mathrm{PGE}_{2} \alpha$ e $\mathrm{PGF}_{2} \alpha$, mediadores essenciais no processo inflamatório ${ }^{12}$. A inibição destas contorções pode estar envolvida com o mecanismo de inibição na gênese de prostaglandinas, apresentando atividade sobre processos inflamatórios. $\mathrm{O}$ grupo tratado com quefir representou inibição de $28 \%$, comparado ao controle, e à indometacina de $36 \%$.

Com base nestes resultados, pode-se sugerir atividade antiinflamatória deste produto (quefir) nos modelos testados, com o envolvimento nas respostas produzidas na formação do granuloma e no processo algogênico por ácido acético.

\section{Materiais e Métodos}

Animais: Foram utilizados ratos (Rattus norvergicus, linhagem Wistar) e camundongos (Mus musculus, albinos) machos, pesando entre 180 - 200 g e 20 - 25 g respectivamente. Foram mantidos em caixas de polietileno $(n=5)$, em ambiente climatizado $\left(23+2{ }^{\circ} \mathrm{C}\right)$, com ração e água ad libitum. Antes dos experimentos, durante 12 horas, permaneceram em jejum.

Quefir: Amostras de quefir armazenadas em nitrogênio líquido foram descongeladas e cultivadas durante 15 dias com troca diária de uma solução $50 \mathrm{~g} / \mathrm{l}$ de açúcar mascavo em água mineral, lavagem dos grãos em água corrente e secagem em temperatura ambiente.

Indução do tecido granulomatoso: O método utilizado foi descrito por Meier ${ }^{9}$ e modificado. O tecido granulomatoso foi obtido pelo implante de quatro cilindros de algodão hidrófilo $(5 \mathrm{~mm}$ de comprimento e $49 \mathrm{mg}$ cada). Esses pelets foram esterilizados ( $121^{\circ} \mathrm{C}, 20 \mathrm{~min}$.) e impregnados com $0,4 \mathrm{ml}$ de solução aquosa de ampicilina 5\% no momento do implante. Com os animais anestesiados, esses pelets foram introduzidos subcutaneamente através de uma incisão abdominal em quatro pontos eqüidistantes. As seguintes drogas foram administradas diariamente (3 grupos, $\mathrm{n}=8$ ): quefir ( $1 \mathrm{ml} / \mathrm{animal}$, v.o.), solução salina $0,9 \%$ ( $1 \mathrm{ml} /$ animal, v.o.) e dexametasona $(0,5 \mathrm{mg} / \mathrm{kg}$, tópico). $\mathrm{O}$ tratamento foi iniciado 2 horas após o implante até o $6^{\circ}$ dia. No $7^{\circ}$ dia, os animais foram sacrificados por decaptação, os granulomas removidos por dissecação e submetidos à secagem em estufa ( 24 horas, $60^{\circ} \mathrm{C}$ ). Seus pesos foram determinados, e o peso do granuloma estabelecido pela diferença entre o peso inicial e final.

Contorções abdominais: O método utilizado foi descrito por $\operatorname{Koster}^{10}$. Grupos de camundongos $(n=8)$ foram tratados com quefir ( $1 \mathrm{ml} /$ animal, v.o.), indometacina (Indocid $®$, Prodome, 10 $\mathrm{mg} / \mathrm{kg}$, v.o.) e água ( $1 \mathrm{ml} / \mathrm{animal}$, v. o.) $30 \mathrm{~min}$. antes da injeção intraperitoneal $(0,25 \mathrm{ml} / \mathrm{animal})$ de uma solução de ácido acético $0,6 \%$ (v/v). O número de contorções abdominais foi obtido durante 20 min., iniciando-se após $5 \mathrm{~min}$ da aplicação do estímulo.

Análise estatística: Os dados foram analisados por ANOVA seguido do teste de comparações múltiplas de Tukey-Kramer $(\mathrm{p}<0,05)$, conforme descrito por Sokal ${ }^{11}$. Os resultados são apresentados por média \pm EPM.

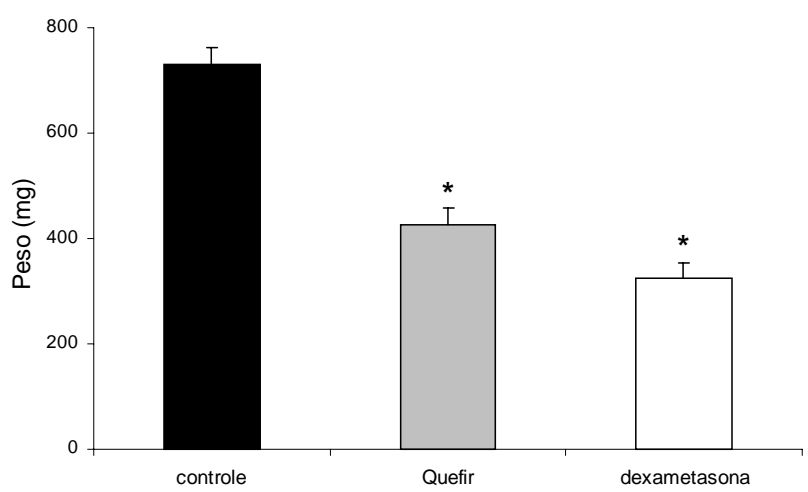

Figura 1. Efeito da administração oral de quefir (1ml/dia) e dexametasona $(0,5 \mathrm{mg} / \mathrm{kg}$, tópico) durante 6 dias sobre a formação do tecido granulomatoso. $\bullet p<0,05$, ANOVA seguido do teste de comparações múltiplas de Tukey-Kramer.

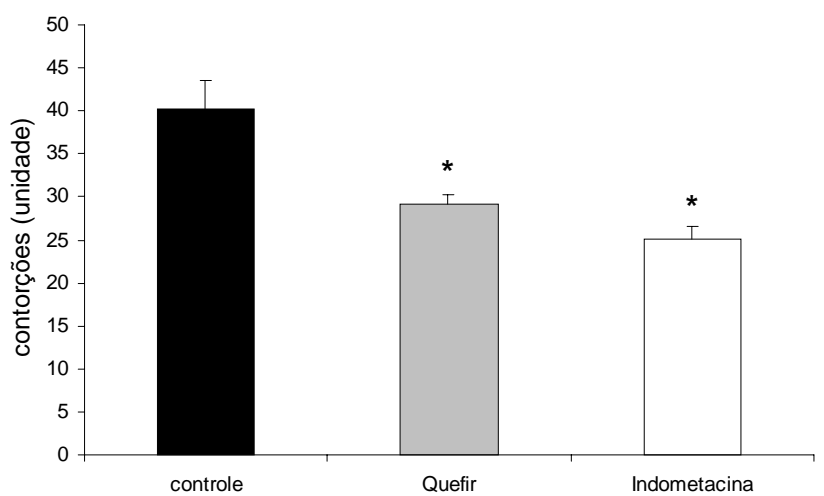

Figura 2. Efeito da administração oral de quefir (1ml) e indometacina $(10 \mathrm{mg} / \mathrm{kg})$ sobre o número de contorções abdominais induzidas por ácido acético. - $\mathrm{p}<0,05$, ANOVA seguido do teste de comparações múltiplas de Tukey-Kramer. 


\section{Referências}

${ }^{1}$ Saloff-Coste, C.J. Kefir. Dannone Newsletter, p. 11, 1998.

2 Toba, T.; Arhara, K.; Adachi, S. Distribution of microorganisms with particular reference to encapsulated characters of fermented milks. Int. J. Food Microbiol., v. 10, n. 3-9, p. 219 224, 1990.

${ }^{3}$ Alm, L. Effect of fermentation on lactose, glucose and galactose content in milk and suitability of fermented milk products for lactose intolerant individuals. J. of Dairy Science,v. 65, n. 3, p. 346-353, 1982.

${ }^{4}$ Ota, A. Protection against an infectious disease by enterohaemorrhagic E.coli 0-157. Med. Hypotheses, v. 53, n.1, p.87- 88, 1999.

${ }^{5}$ Pool-Zobel, B.L.; Munzner, R.; Holzapfel, W.H. Antigenotoxic properties of lactic acid bacteria in the S. typhimuriium atagenicity assay. Nutr. Cancer, v. 20, n. 3, p. 261 - 270, 1993.

${ }^{6}$ Orlova, Z.N.; Kasatkina, T.N.; Okhapkina, V.F. Use of Robolact and Linolac dry milk mixtures in the overall therapy of infants with acute intestinal infections. Vopr. Pitan., v. 4, p. 45 - 47, 1980.

${ }^{7}$ Kubo, M.; Odani, T.; Nakamura S. Pharmacological study on kefir - a fermented milk product in Caucasus. I. On tumor activity. Yakugaku Zsshi, v. 112, n. 7, p. 489 - 495, 1992.

${ }^{8}$ Schmidt, P.; Vass. A.; Szakaly, S. Effect of fermented milk diets on regeneration of the rat liver. Acta Med. Hung., v. 41 n. 2-3, p. 163-169, 1984.

${ }^{9}$ Meier, R.; Schuler, W.; Desaulles, P.; Zur frage des mechanismus der hemmung des bindegewebswachstums durch cortisone. Experientia (Basel), v.6, p. 469 - 471, 1950.

${ }^{10}$ Koster, R.; Anderson, M.; Beer, E.J. Acetic acid for analgesic screening. Federation Proceedings v. 18, p. 412 - 416, 1959.

${ }^{11}$ Sokal, R.R.; Rohlf. F.J. Biometry, W.H. Freeman, W.H. (Ed.), San Francisco, p. 175 - 205; 404 - 486, 1995.

${ }^{12}$ Deraedt, R., Jouquey, S., Delevallee, F., Flahaut, M. Release of prostaglandins $\mathrm{E}$ and $\mathrm{F}$ in an algogenic reaction and its inhibition. European J. Pharmacol., v. 61, p. 17-24, 1980.

*Autor para correspondência:

Prof. Dr. José Carlos Tavares Carvalho

Laboratório de Fitofármacos

Universidade de Alfenas

Rod. MG 179, Km 0, CP 23 - CEP 37130-000 - Alfenas (MG)

Email: zemas@hotmail.com

\section{Avaliação da atividade antibacteriana e antifúngica de extratos de plantas utilizados na medicina popular}

Pessini, G.L.; Holetz, F.B.; Sanches, N.R.; Cortez, D.A.G.; Dias

Filho, B.P.; Nakamura, C.V.*

Programa Pós-graduação em Ciências Farmacêuticas Universidade Estadual de Maringá

\section{Resumo}

Foram selecionados extratos de 13 plantas utilizadas na medicina popular brasileira para avaliar a atividade antimicrobiana. Destes, 10 extratos apresentaram níveis variados de atividade antibacteriana. Cinco dos extratos testados, apresentaram compostos com valores de $\mathrm{Rf}$ similares a de compostos antibacterianos visíveis na bioautografia. Três destas plantas pertencem à família Compositae indicando que o mesmo composto pode ser responsável pela atividade antibacteriana destas plantas. Atividade anticandida foi observada em 9 extratos de plantas. Os resultados podem explicar o uso etnobotânico das espécies estudadas para o tratamento de várias doenças infecciosas

\begin{abstract}
Extracts of 13 Brazilian medicinal plants were screened for their antimicrobial activity against bacteria and yeast. Of these, 10 plant extracts showed varied levels of antibacterial activity. Five of the plant extracts presented compounds with $\mathrm{Rf}$ values similar to the antibacterial compounds visible on bioautogram. Of these, three plants belong to the Compositae family. This may mean that the same compounds are responsible for the antibacterial activity in these plants. Anticandidal activity was detected in 9 plant extracts. The results might explain the ethnobotanical use of the studied species for the treatment of various infectious diseases.
\end{abstract}

O uso de plantas medicinais especialmente na América do Sul contribui significantemente para os cuidados básicos com a saúde. Para o tratamento de infecções comuns, muitas plantas são utilizadas no Brasil na forma de extrato bruto, infusões ou emplastos, sem nenhuma evidência científica de sua eficácia. Recentemente demonstramos a atividade antibacteriana do óleo essencial e do composto ativo purificado (eugenol) extraído do Ocimum gratissimum, tradicionalmente usado na medicina popular brasileira para o tratamento de várias doenças ${ }^{1}$. Mais recentemente, Alves e colaboradores ${ }^{2}$ realizaram um trabalho com cerca de 60 espécies de plantas medicinais 